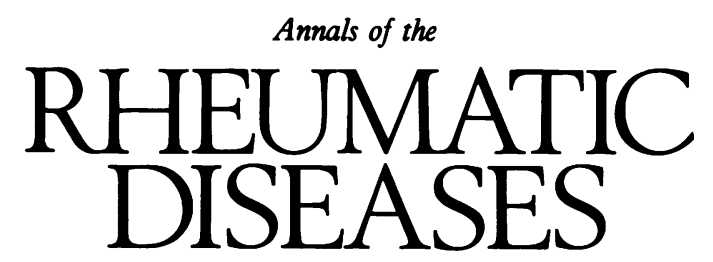

Leader

\title{
HLA-B27 subtypes: implications for the spondyloarthropathies
}

Nineteen years after its discovery, the strong association between HLA-B27 and the spondyloarthropathies remains an enigma. Several reviews have dealt with the molecular biology of B27,,$^{1-3}$ and Schwartz $Z^{4}$ and Ivanyi ${ }^{5}$ have given lucid accounts of hypotheses for the mechanism of the B27spondyloarthropathy association. Discussion here concentrates on the HLA-B27 subtypes and their implications for postulated disease mechanisms.

\section{HLA-B27 structure, function, and subtypes}

Seven B27 subtypes are defined by DNA sequence. ${ }^{6}$ Six of these differ by charged amino acids and can be discriminated by isoelectric focusing. ${ }^{7}$ From basic to acidic they are designated $\mathrm{B}^{*} 2701$ (isoelectric point (pI) 5.94) to $\mathrm{B}^{*} 2706$ (pI 5.57). The seventh ( $B^{*} 2707$, formerly 'B27HS') has an isoelectric point close to that of $B^{*} 2701$, but its DNA sequence differs by eight amino acids. ${ }^{8}$ All the subtypes are recognised by conventional human post-partum B27 antisera. Subtypes have also been detected by mouse monoclonal antibodies and human antisera, ${ }^{9}$ alloreactive cytotoxic $\mathrm{T}$ lymphocyte lines ${ }^{10}{ }^{11}$ and clones, ${ }^{1}$ and at the DNA level by sequencing or hybridisation with complementary oligonucleotides. ${ }^{12}$ About $90 \%$ of B27 positive European caucasoids are $B^{*} 2705$ (formerly B27 1, B27w or B27a; pI 5.66). $B^{*} 2707$ was found in an Asian Indian family and probably results from recombination between $B^{*} 2705$ and another HLA-B gene. The other subtypes have arisen from B* 2705 by point mutations, the sites of which are shown in the figure. The second most common caucasoid subtype is B*2702 (B27.2, or B27K, or B27e; pI 5.80), which differs from B*2705 by three substitutions: Asn for Asp at amino acid position 77, Ile for Thr at 80, and Ala for Leu at 81 . B*2703 is limited to black subjects (among whom HLA-B27 is unusual), and $B * 2704$ and $B * 2706$ to oriental subjects. $B^{*} 2701^{7}$ and $B^{*} 2707$ have each been found by one group in single kindreds, and have yet to be detected in other published surveys.

The tertiary structure of HLA-B $* 2705$, determined by $x$ ray crystallography, ${ }^{13}$ is similar to that of $\mathrm{HLA}-\mathrm{A} 2^{14}$ and HLA-A68, ${ }^{15}$ with a central, peptide binding cleft between $\alpha$ helices (figure). Unlike A2 or A68, a salt bridge spans the cleft. It is likely that the other subtypes have a similar overall configuration. The main peptide cleft has six smaller side pockets (designated A-F)-notably, an acidic, hydrophilic recess extending under the $\alpha_{1}$ helix (left hand end of the upper helix in the figure) towards residue 45 , the '45' or B pocket. ${ }^{16}$ Peptides bound to B27 extend along the groove, and B27 and peptide form a tight complex with the peptide side chains interacting with complementary sites on B27. Eleven peptides eluted from $B^{*} 2705$ and the previously known $B 27$ restricted viral peptides share striking features ${ }^{17}$ : they are positively charged nonamers with an invariant arginine residue at position $2(\mathbf{P} 2)$, extending into the B pocket and interacting with a cysteine residue at position 67 on B27. P1 and P9 are usually positively charged, P3 is hydrophobic, and P6 favours a non-polar or small polar residue. Several $B^{*} 2705$ restricted peptides can be bound and presented by some $B^{*} 2702$ cell lines, ${ }^{18}$ but detailed peptide data for other subtypes are lacking.

Breur-Vriesendorp and colleagues found that the B27 subtype distribution in Dutch caucasoid and oriental patients with ankylosing spondylitis was similar to that in healthy controls. ${ }^{11}$ We have recently confirmed this observation in caucasoid British patients, and extended it to reactive arthritis and to small numbers of Asian Indian patients with spondyloarthropathies (MacLean et al, unpublished data). A Spanish study found that the same proportion of subjects in B27 positive healthy groups and groups with ankylosing spondylitis and Reiter's syndrome reacted with the B27M2 monoclonal antibody, ${ }^{19}$ which recognises $B^{*} 2705$ but not $B^{*} 2701$ or $B^{*} 2702$. The original

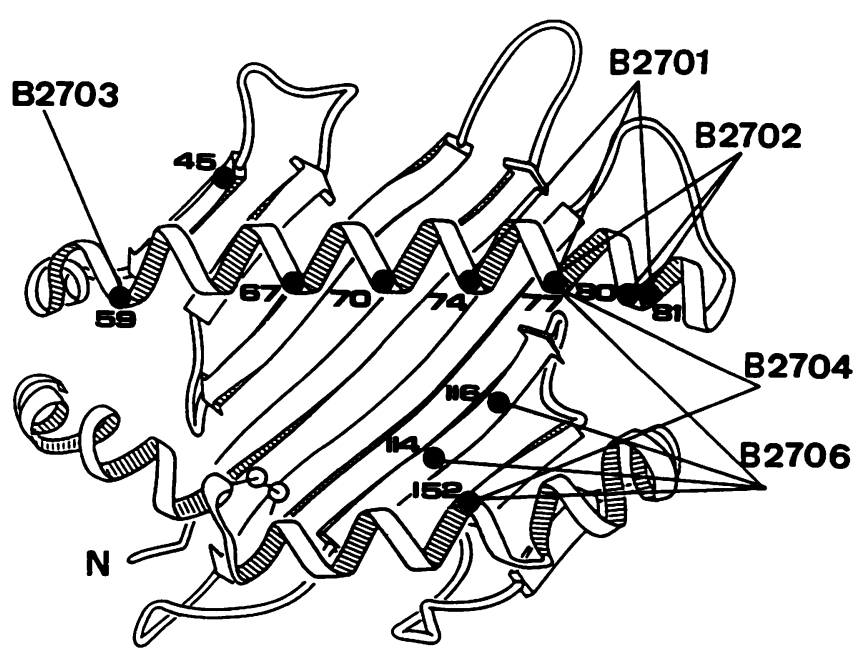

Positions of amino acid residues determining HLA-B27 subtypes; $B^{*} 2707$ not shown. Ribbon representation of amino acid chains, modelled on HLA-A2 crystallographic structure. Structures shown on the lefi hand side of the molecule, spatially removed from the amino acids which determine subtype, are likely to be involved in spondyloarthropathies. (Modified and reproduced, with permission, from reference 1 .) 
B*2701 'proband' had advanced, teenage onset ankylosing spondylitis (Choo S Y, personal communication). Using subtyping with cytotoxic $\mathrm{T}$ lymphocytes and isoelectric focusing, the Dutch study found both B*2704 and B*2706 in oriental subjects with ankylosing spondylitis. ${ }^{11}$

Although the subtype distribution in non-white subjects and in patients with spondyloarthropathies other than ankylosing spondylitis needs clarification by further study, the information now available indicates that spondyloarthropathies occur in at least five B27 subtypes. At a molecular level this implies that the portions of the HLAB27 molecule which determine subtype are not critically involved in disease pathogenesis. The pathogenic features must be unique to B27, as compared with other HLA molecules, but shared between the subtypes. When individual amino acid sites are considered, only the lysine residue at amino acid position 70 fulfils these criteria. ${ }^{8}$ Alternatively, a combination of spatially related residues at positions 9 (His), 45 (Glu), 67 (Cys), 70 (Lys), 71 (Ala), and 97 (Asn), all to the left hand portion of the molecule as shown in the figure and close to the B pocket, can define B27. ${ }^{16}$ With the exception of the position 59 substitution on B* 2703 and the position 97 substitution on B* 2707 (antigens whose relation to spondyloarthropathies is unknown), the residues determining subtype are physically distant from this portion of the molecule. What implications does this have for the different B27-spondyloarthropathy models?

\section{Mechanisms for the spondyloarthropathy-HLA-B27 association \\ LINKED GENE MODEL}

There are at least 40 non-HLA genes in the human major histocompatibility complex. Susceptibility to spondyloarthropathies might be due to an adjacent 'disease susceptibility gene ${ }^{20}$ rather than to B27 itself. On the basis either of amino acid sequence ${ }^{5}$ or of cytotoxic T lymphocyte recognition' some of the B27 subtypes are as different from each other as are discrete polymorphic HLA alleles, and a large proportion of HLA polymorphism predates human speciation. ${ }^{21}$ The racial distribution of the B27 subtypes implies a more recent origin, but their precise antiquity is open to speculation. In the linked gene model the disease susceptibility gene must have arisen earlier in human evolution than the subtypes, and then subsequently conserved in close approximation to the B27 gene. Alternatively, it might have arisen independently in association with each of the spondyloarthropathy linked subtypes. Although not impossible, these options seem unlikely. The HLA-B27 transgenic rat model of spondyloarthropathies is also suggestive of a direct role for B27,, 22 and most workers now favour involvement of B27 itself in spondyloarthropathies.

\section{PATHOGENIC PEPTIDE}

The physiological function of HLA antigens is the presentation of processed antigenic peptides to the $T$ cell receptor, to trigger the 'cellular' arm of the immune system. B27 might have a unique ability to present a particular 'pathogenic peptide'. This might alter the potential immune response repertoire through self tolerance of a B27 plus endogenous peptide complex, or initiate an immune response not possible with other HLA alleles. In this model the pathogenic peptide would need to be presented by all the B27 subtypes associated with the spondyloarthropathies.

Hill and colleagues speculated that the predominance of HLA-B*2703 in B27 positive Gambian black subjects might explain the rarity of spondyloarthropathies in this population. ${ }^{12} B^{*} 2703$ differs from $B * 2705$ by a single amino acid substitution (Tyr to His) at position 59. Amino acid position
59 faces the peptide binding cleft and is physically distant from residues determining other (spondyloarthropathy linked) subtypes. $B^{*} 2703$ shares the regions whose uniqueness to B27 is central to other pathogenic models (see below). Thus although other genetic and environmental factors might equally be involved in the paucity of spondyloarthropathies in African black subjects, this favours the pathogenic peptide model. HLA-B27 molecules require the presence of antigenic peptide to assemble and fold correctly, ${ }^{23}$ and additional indirect evidence for this model comes from the observation that the $B^{*} 2705$ transgenic rats show a dramatic rise in B27 expression with the onset of spondyloarthropathy-like disease. ${ }^{24}$ On the other hand, Breur-Vriesendorp et al found that B*2705 restricted, influenza specific cytotoxic $T$ lymphocytes recognised infected $B * 2703$ cells, and vice versa, arguing against a significant effect of the position 59 mutation on peptide binding. ${ }^{25}$

\section{MOLECULAR MIMICRY}

A six amino acid sequence homology between B27 and the iron binding component of the Klebsiella pneumoniae nitrogenase reductase enzyme complex has been proposed as evidence supporting 'molecular mimicry' in the spondyloarthropathies. ${ }^{26}$ The hexapeptide homology was with B*2705 only, however; pentapeptide homology with $B^{*} 2702$ was common to several other (not disease associated) HLA alleles. It is conceivable that alternative mechanisms account for spondyloarthropathies in patients with other subtypes, just as we cannot escape the fact that spondyloarthropathies occur in B27 negative subjects. Other reported B27 enterobacterial sequence homologies are not limited to B*2705, but again are common to HLA alleles not linked with spondyloarthropathies.

\section{RECEPTOR MODEL}

Geczy's demonstration of a cross reaction between certain enterobacteria and B27 positive ankylosing spondylitis cells (but not with healthy B27 or B27 negative ankylosing spondylitis cells), and the ability of plasmid coded, low molecular weight, bacterial components to modify normal B27 cells such that they share this cross reaction ${ }^{27}$ - the basis of the 'receptor' hypothesis-has not been reliably reproduced. The three dimensional structure of HLA molecules and their presumed physiological function in binding peptides are entirely compatible with action as a receptor; whether B27 offers anything unusual in this respect remains to be determined.

The sulphydryl (-SH; thiol) bearing side chain of the unpaired cysteine at amino acid position 67 is an attractive candidate for a binding site for exogenous products, ${ }^{28}$ and this cysteine is critical to the antigenic structure of B27. ${ }^{29}$ The adjacent positively charged lysine side chain $\left(-\mathrm{NH}_{3}^{+}\right)$at amino acid position 70 , shared between the spondyloarthropathy linked subtypes and so far unique to B27, may favour a more reactive $-S^{\bullet}$ cysteine variant at position $67 .{ }^{30}$ Although the B27 crystal structure suggests that the sulphydryl side chain would be buried beneath processed antigenic peptide, ${ }^{13}$ Benjamin $e t$ al have evidence that a high proportion of cell surface B27 molecules lack bound peptide. ${ }^{31}$ Thus even if the crystallographic structure accurately reflects B 27 in vivo, a proportion of sulphydryl sites would be accessible. sulphydryl side chain of the position 67 cysteine $^{30}$ are 
sufficient to provoke an immune response, by resembling a foreign antigen or by binding a non-standard peptide. Assessment of the oxidative state of this cysteine has proved technically difficult. Attempts to measure the effect on B27 antigenicity of reagents which bind sulphydryl yielded poorly reproducible results, with the effect varying according to the methods used. ${ }^{32} 33$ Flow cytometry suggested that less than $30 \%$ of cell surface B27 molecules have an accessible reactive cysteine. Alternative methods will be required to characterise this site further.

In summary, the existence of spondyloarthropathies in multiple HLA-B27 subtypes strongly supports the involvement of the B27 antigen itself directly in the disease process, and argues against the significance of microbial sequence homology with a single subtype. Features of the HLA-B27 molecule shared between the disease linked subtypes, but unique to B27 among HLA antigens, are involved in the pathogenesis of spondyloarthropathies. The main existing hypotheses (pathogenic peptide, receptor, molecular mimicry, and altered self) remain equally plausible, and B27 subtyping has been unhelpful in favouring any one mechanism. Although theoretically attractive, there is no prima facie evidence that B27 causes disease by a 'conventional' action as a peptide presenter.

I thank Dr J R Archer for helpful comments.

Orpington Hospital,

Kent BR6 9fU,

LACHY MACLEAN

United Kingdom

1 Lopez de Castro J A, Bragado R, Lauzurica P, Lopez D, Rojo S. Structure and immune recognition of HLA-B27 antigens: implications for disease association. Scand $\mathcal{J}$ Rheumatol Suppl 1990; 87: 21-31.

2 Woodrow J C. Genetics of the spondyloarthropathies. Curr Opin Rheumatol 1991; 3: 586-91.

3 Lipsky P E, Taurog J D. The second international Simmons Center conference on HLA-B27-related disorders. Arthritis Rheum 1991; 34: 1476-82.

4 Schwart\% B D. Infectious agents, immunity, and rheumatic diseases. Arthritis Rheum 1990; 33: 457-65.

5 Ivanyi P. Dysfunction of HLA-B27. Scand f Rheumatol Suppl 1990; 87: 51-69.

6 Bodmer J G, Marsh S G E, Albert E D, et al. Nomenclature for factors of the HLA system, 1991. Tissue Antigens. In press.

7 Choo S Y, Antonelli P, Nisperos B, Nepom G T, Hansen J A. Six variants of HLA-B27 identified by isoelectric focusing. Immunogenetics 1986; 23: 24-9.

8 Choo S Y, Fan L-F, Hansen J A. A novel HLA-B27 allele maps B27 allospecificity to the region around position 70 in the $\alpha 1$ domain. 7 Immunol 1991; 147: 174-80.

9 de Waal L P, Krom F E J M, Breur-Vriesendorp B S, Engelfriet C P, Lope\% de Castro J A, Ivanyi $P$. Conventional alloantisera can recognise the same HLA-B27 polymorphism as detected by cytotoxic T lymphocytes. Hum Immunol 1987; 20: 265-71.
10 Breuning M H, Lucas C J, Breur B S, et al. Subtypes of HLA-B27 detected by cytotoxic $\mathrm{T}$ lymphocytes and their role in self-recognition. Hum Immunol 1982; 5: 259-68.

11 Breur-Vriesendorp B S, Dekker-Saeys A J, Ivanyi P. Distribution of HLAB27 subtypes in patients with ankylosing spondylitis: the disease is associated with a common determinant of the various B27 molecules. Ann Rheum Dis 1987; 46: 353-6.

12 Hill A V S, Allsopp C E M, Kwiatkowski D, Anstey N M, Greenwood B M McMichael A J. HLA class I typing by PCR: HLA-B27 and an African B27 subtype. Lancet 1991; 337: 640-2.

13 Madden D R, Gorga J C, Strominger J L, Wiley D C. The structure of HLAB27 reveals nonamer self-peptides bound in an extended conformation. Nature 1991; 353: 321-5.

14 Bjorkman P J, Saper M A, Samraoui B, Bennett W S, Strominger J L, Wiley D C. Structure of the human class I histocompatibility antigen, HLA-A2 Nature 1987; 329: 506-12.

15 Garrett T P J, Saper M A, Bjorkman P J, Strominger J L, Wiley D C. Specificity pockets for the side chains of peptide antigens in HLA-Aw68. Nature 1989; 342: 692-6.

16 Buxton S E, Benjamin R J, Clayberger C, Parham P, Krensky A M Anchoring pockets in human histocompatibility complex leukocyte antigen B27. F Exp Med 1992; 175: 809-19.

17 Jardetzky T S, Lane W S, Robinson R A, Madden D R, Wiley D C Identification of self peptides bound to purified HLA-B27. Nature 1991 353: 326-9.

18 Pazmany L, Rowland-Jones S, Huet S, et al. Genetic modulation of antigen presentation by HLA-B27 molecules. $\mathcal{f}$ Exp Med 1992; 175: 361-9.

19 Sanmarti R, Canete J D, Collado A, Brancos M A, Rotes-Querol J, Ercilla M G. HLA-B27 subtypes and seronegative spondyloarthropathies. Clin Exp Rheumatol 1989; 7: 102-3.

20 McDevitt H O, Bodmer W F. HLA immune response genes, and disease Lancet 1974; i: 1269-75.

21 Lawlor D A, Ward F E, Ennis P D, Jackson A P, Parham P. HLA-A and B polymorphisms predate the divergence of humans and chimpanzees. Nuturc 1988; 335: 268-71.

22 Hammer R E, Maika S D, Richardson J A, Tang J-Y, Taurog J D. Spontaneous inflammatory disease in transgenic rats expressing HLA-B27 and human $\mathrm{B}_{2} \mathrm{~m}$ : an animal model of HLA-B27-associated human disorders. Cell 1990; 63: 1099-112.

23 Kvist S, Hamann U. A nucleoprotein peptide of influenza A virus stimulates assembly of HLA-B27 class I heavy chains and $\hat{B}_{2}$-microglobulin translated in vitro. Nature 1990; 348: 446-8.

24 Taurog J D, Maika S D, Hlavaty J L, et al. Inflammatory disease in HLA-B27 transgenic rats is accompanied by a dramatic rise in B27 expression [Abstract]. Arthritis Rheum 1991; 34 (suppl): S33.

25 Breur-Vriesendorp B S, Vigerhoed J, Kuijpers K C, et al. Effect of a Tyr-toHis point-mutation at position 59 in the alpha-1 helix of the HLA-B27 classI molecule on allospecific and virus-specific $T$ lymphocyte recognition. Scand F R heumatol Suppl 1990; 87: 36-43.

26 Schwimmbeck P L, Yu DT Y, Oldstone M B A. Autoantibodies to HLA-B27 in the sera of HLA-B27 patients with ankylosing spondylitis and Reiter's syndrome. F Exp Med 1987; 166: 173-81.

27 Geczy A F, Alexander K, Bashir H V, Edmonds J. A factor(s) in klebsiella culture filtrates specifically modifies an HLA-B27-associated cell-surface component. Nature 1980; 283: 782-4.

28 Ezquerra A, Bragado R, Vega M A, Strominger J L, Woods J, Lope: de Castro J A. Primary structure of a papain-solubilised human histocompatibility antigen HLA-B27. Biochemistry 1985; 24: 1733-41.

29 El-Zaatari F A K, Sams K C, Taurog J D. In vitro mutagenesis of HLA-B27. Amino acid substitutions at position 67 disrupt anti-B27 monoclonal antibody binding in direct relation to the size of the substituted side chain. f Immunol 1990; 144: 1512-7.

30 Archer I R, Whelan M A, Badakere S S, MacLean I L, Archer I V J, Winrow $V R$. Effect of a free sulphydryl group on expression of HLA-B27 specificity. Scand f Rheumatol Suppl 1990; 87: 44-50.

31 Benjamin R J, Madrigal J A, Parham P. Peptide binding to empty HLA-B27 molecules of viable human cells. Nature 1991; 351: 74-7.

32 MacLean I L, Perrett D, Winrow V R, Archer J R. Status of an unpaired thiol group on the HLA-B27 epitope. Clin Exp Immunol 1989; 77: 417-21.

33 MacLean L, Macey M, Lowdell M, et al. Sulphydryl reactivity of the HLA B27 epitope: accessibility of the free cysteine studied by flow cytometry. Ann Rheum Dis 1992; 51: 456-60. 